\title{
Efeito das condições de queima na estabilização de um resíduo rico em $\mathrm{CaCO}_{3} \mathrm{em}$ massa argilosa
}

\section{(Effect of firing conditions on stabilization of a waste rich in $\mathrm{CaCO}_{3}$ in clayey mass)}

\author{
L. R. Rodrigues ${ }^{1 *}$, V. P. Della Sagrillo ${ }^{2}$, A. S. dos Reis ${ }^{2}$ \\ ${ }^{1}$ Universidade Federal de São Carlos, Rd. Washington Luiz, km 235, 13565-905, S. Carlos, SP, Brasil \\ ${ }^{2}$ Instituto Federal do Espírito Santo, 29040-780, Vitória, ES, Brasil
}

\begin{abstract}
Resumo
A substituição de matéria-prima argilosa por resíduos industriais é uma alternativa para redução da exploração do mineral e do impacto ambiental. Nesse trabalho, o dregs (resíduo inorgânico rico em carbonato de cálcio) gerado na fabricação de celulose, foi adicionado a uma argila caulinítica nos teores de 10\%, 20\%, 30\% e 40\% (em massa). Os corpos de prova (CPs) prensados foram sinterizados em 850,950 e $1050{ }^{\circ} \mathrm{C}$ com patamar de 180 min e em 850 e $950{ }^{\circ} \mathrm{C}$ com patamar de 300 min, visando avaliar a influência do ciclo de queima nas propriedades dos CPs. Em seguida, foram medidas as propriedades físico-mecânicas e avaliado o desenvolvimento de eflorescência, além da realização de análises por MEV e DRX após imersão dos CPs em água. Apesar da obtenção de valores satisfatórios nas propriedades físico-mecânicas após sinterização com patamar de 180 min, a presença de $\mathrm{CaCO}_{3}$ não reagido tornou necessário patamar de 300 min em $950{ }^{\circ} \mathrm{C}$ para aplicação do dregs em teores de até $20 \%$ em massa.

Palavras-chave: massa argilosa, dregs, carbonato de cálcio.
\end{abstract}

\begin{abstract}
The replacement of clayey raw material by industrial wastes is an alternative to reduce mineral exploration and environmental impact. In this study, dregs (inorganic waste rich in calcium carbonate generated by the cellulose pulp production) was added to a kaolinitic clay in the contents of 10, 20, 30, and $40 \mathrm{wt} \%$. The specimens prepared by uniaxial pressing were sintered at 850 , 950, and $1050{ }^{\circ} \mathrm{C}$ with a holding time of $180 \mathrm{~min}$, and at 850 and $950{ }^{\circ} \mathrm{C}$ with a holding time of 300 min, aiming to evaluate the influence of firing cycle on the properties of specimens. Then, physical-mechanical properties were measured, and efflorescence development was evaluated, besides the SEM and XRD analysis of specimens after water immersion. Even though satisfactory physical-mechanical properties were achieved after sintering with 180 min holding time, the presence of unreacted CaCO made necessary the sintering at $950^{\circ} \mathrm{C}$ and holding time of 300 min to use up to $20 \mathrm{wt} \%$ dregs.
\end{abstract}

Keywords: clayey mass, dregs, calcium carbonate.

\section{INTRODUÇÃO}

Em 2018 a produção de celulose no Brasil foi de 21,1 milhões de toneladas, representando crescimento de $8,0 \%$ em relação ao ano anterior, o que mantém o país como o segundo maior produtor de celulose do mundo [1]. Associado ao crescimento na produção, também há aumento no volume de resíduos sólidos gerados. Durante muitos anos o principal destino desses resíduos foi a disposição em aterros. Contudo, regulamentações ambientais têm aumentado o custo dos aterros, tornando necessário minimizar a formação e disposição de resíduos sólidos da indústria de papel e celulose [2]. Dessa forma, é importante a valorização dos resíduos desse segmento industrial, a fim

*lorena.raphael92@gmail.com

Dhttps://orcid.org/0000-0002-7270-6040 de reduzir os custos relacionados à disposição, bem como os impactos ambientais. Diversas etapas da indústria de papel e celulose levam à formação de resíduos sólidos, cuja quantidade e composição é dependente do tipo de papel produzido, da matéria-prima utilizada e das técnicas utilizadas nos processos. A maior parte dos resíduos produzidos na fabricação de papel e celulose envolve lodo da estação de tratamento de água, lama de cal, grits, dregs, cinzas da caldeira e resíduos do processamento da madeira. Normalmente, esses resíduos sólidos são removidos úmidos e contêm compostos orgânicos, além de traços de metais pesados [3].

No processo Kraft, o principal usado na fabricação de polpa de celulose, após a dissolução da lignina para separação das fibras de celulose, é feita a recuperação química dos reagentes no licor negro. Nessa etapa é feita a caustificação, onde o carbonato de sódio inativo é convertido em hidróxido de sódio, utilizado na digestão da celulose. Na clarificação 
do licor obtido (licor verde) são removidos os compostos insolúveis, que contêm metais e outros componentes não processuais. Esse resíduo precipitado é denominado dregs [2]. O elemento presente em maior quantidade no dregs é o Ca, seguido de $\mathrm{Mg}$ e $\mathrm{Na}$ [4]. Contudo, deve-se ressaltar que sua composição varia de acordo com as matériasprimas e parâmetros de processo de cada planta industrial. Por ser um material alcalino, composto essencialmente de $\mathrm{CaCO}_{3}$ [5], alguns autores já estudaram a utilização do dregs como agente neutralizador de águas residuais $[2,6]$ e solos [7]. Devido à elevada capacidade de incorporação de subprodutos industriais em massas argilosas, outra possibilidade para o aproveitamento de resíduos da indústria de celulose é como matéria-prima alternativa em materiais cerâmicos. Diversos tipos de resíduos já foram estudados como substitutos parciais da argila em formulações de produtos cerâmicos, como: resíduo de rochas ornamentais [8]; borra de petróleo [9]; resíduo de mármore [10]; lama vermelha [11]; adição simultânea de areia descartada de fundição e escória do processo Waelz [12]; lodo galvânico [13]; e resíduo de vidro sodo-cálcico [14].

Entretanto, há poucos estudos visando o uso do dregs em cerâmicas argilosas. Por ex., foram avaliadas a incorporação de dregs em até $10 \%$ em massa em cerâmica vermelha [15] e a possibilidade de combinação de dregs e outros resíduos da indústria de celulose para obtenção de produtos de cerâmica vermelha $[16,17]$. Em estudo anterior [18], os autores do presente estudo também avaliaram a potencialidade de incorporação de dregs em cerâmica vermelha. Essas pesquisas indicam a possibilidade de utilização do dregs em cerâmica vermelha, entretanto, não foi verificado como as condições de queima influenciam nas propriedades físico-mecânicas do produto, bem como se esse resíduo leva ao desenvolvimento de eflorescência, um defeito comum em cerâmica tradicional, que pode comprometer a aparência e durabilidade da peça. Dessa forma, o objetivo desse trabalho foi avaliar o efeito da incorporação de dregs e do ciclo de queima nas propriedades tecnológicas de massas argilosas. Assim, foram variados o percentual de resíduo, o tempo de patamar e a temperatura máxima de queima.

\section{MATERIAIS E MÉTODOS}

Foram utilizados uma argila caulinítica, extraída de Minas Gerais, e o resíduo inorgânico dregs fornecido por uma indústria de polpa de celulose localizada na Bahia. As massas com adição de $0,10 \%, 20 \%, 30 \%$ e $40 \%$ em massa de dregs foram preparadas com as matérias-primas secas em estufa a $110^{\circ} \mathrm{C}$ por $24 \mathrm{~h}$, desaglomeradas manualmente, e peneiradas em malha com abertura de 0,250 $\mathrm{mm}$. Esse procedimento teve o objetivo de garantir a ausência de aglomerados nos corpos de prova conformados. Após mistura e umidificação com $10 \%$ em massa de água, foram conformados por prensagem uniaxial em prensa hidráulica utilizando matriz de aço e pressão de $25 \mathrm{MPa}$ corpos de prova (CPs) com as dimensões de $60 \times 20 \times 5 \mathrm{~mm}^{3}$. Os CPs prensados foram secos em estufa a $110{ }^{\circ} \mathrm{C}$ durante $24 \mathrm{~h}$ e, em seguida, sinterizados em forno tipo mufla (Fortelab, ME 1700) em atmosfera oxidante utilizando os ciclos de queima indicados na Tabela I. Em todos os ciclos foi utilizada taxa de aquecimento de $2{ }^{\circ} \mathrm{C} / \mathrm{min}$. O resfriamento até a temperatura ambiente foi realizado por convecção natural, mantendo os CPs dentro do forno.

Tabela I - Dados dos ciclos de queima empregados. [Table I - Data of firing cycles.]

\begin{tabular}{ccc}
\hline Ciclo & $\begin{array}{c}\text { Temperatura } \\
\text { máxima } \\
\left({ }^{\circ} \mathrm{C}\right)\end{array}$ & $\begin{array}{c}\text { Tempo de patamar } \\
(\mathrm{min})\end{array}$ \\
\hline 1 & 850 & \\
2 & 950 & 180 \\
3 & 1050 & \\
\hline 4 & 850 & 300 \\
5 & 950 & \\
\hline
\end{tabular}

Os CPs sinterizados tiveram sua absorção de água e tensão de ruptura à flexão (3 pontos) determinadas de acordo com metodologias sugeridas em [19]. Em cada ensaio foram utilizados 6 CPs de cada formulação. Foi realizado tratamento estatístico dos resultados utilizando análise de variância (ANOVA) com nível de confiança de $95 \%$ e teste de Tukey para verificar se a variação das propriedades avaliadas com a alteração do ciclo de queima foi significativa. $O$ fator considerado para a ANOVA foi apenas a variação no ciclo de queima (ANOVA de fator único). Para avaliar o desenvolvimento de eflorescência e/ou de depósitos brancos de calcita devido à não reatividade do resíduo, foi realizado ensaio com base na norma ASTM C67-16 [20], que consistiu em imergir parcialmente os CPs em água destilada durante 7 dias e, em seguida, colocá-los em estufa a $110^{\circ} \mathrm{C}$ durante 24 h. Após secagem, foi feita análise visual para verificar se houve alteração na aparência da superfície dos CPs na presença de água. Segundo a norma, o ensaio deve ser realizado em tijolos, contudo, por ser apenas uma análise qualitativa, o emprego dos CPs não interferiu nas conclusões obtidas. A superfície dos CPs em que foi observada aparência esbranquiçada foi caracterizada por difração de raios X (DRX) e microscopia eletrônica de varredura (MEV). A análise por DRX foi realizada em difratômetro (Brucker, D8 Advance) utilizando radiação $\mathrm{CuK} \alpha$ e intervalo de varredura de $10^{\circ}$ a $100^{\circ}(2 \theta)$. A interpretação das fases presentes no difratograma foi efetuada por meio do software Diffrac.Eva (base de dados ICDD-PDF). A avaliação das amostras por MEV foi feita utilizando microscópio (Zeiss, EVO MA10) com espectrômetro de energia dispersiva (EDS) acoplado. O mapeamento elementar da superfície por EDS foi realizado para identificar os componentes químicos presentes e sua distribuição nos depósitos observados na superfície dos CPs. 


\section{RESULTADOS E DISCUSSÃO}

Em pesquisa anterior [18] foi verificado que a argila utilizada teve como principais componentes $\mathrm{SiO}_{2}$ e $\mathrm{Al}_{2} \mathrm{O}_{3}$, encontrados na forma de caulinita. Já o resíduo (dregs) foi composto de calcita $\left(\mathrm{CaCO}_{3}\right)$, além dos óxidos fundentes $\mathrm{Na}_{2} \mathrm{O}$ e $\mathrm{MgO}$, em percentuais superiores a $5 \%$, permitindo que a incorporação desse material em massas argilosas seja benéfica à etapa de queima, por facilitar a formação de fase líquida durante o tratamento térmico. Como os ciclos de queima utilizados apresentaram temperatura máxima acima de $850{ }^{\circ} \mathrm{C}$ era esperado que todo carbonato presente na formulação fosse calcinado durante o tratamento térmico, pois a decomposição do $\mathrm{CaCO}_{3}$ do resíduo ocorre em temperaturas abaixo de $850^{\circ} \mathrm{C}[18,21]$.

Os corpos de prova (CPs) com adição de até $40 \%$ dregs tiveram sua absorção de água (AA) e resistência à flexão medidas. Nas Figs. 1a e $1 \mathrm{~b}$ nota-se que a AA teve tendência a aumentar com o percentual de dregs adicionado. Devido à $\mathrm{AA}$ estar relacionada à porosidade aberta do $\mathrm{CP}$, esse comportamento também indicou aumento na porosidade, que foi decorrente de parte do resíduo ser volatilizado durante a
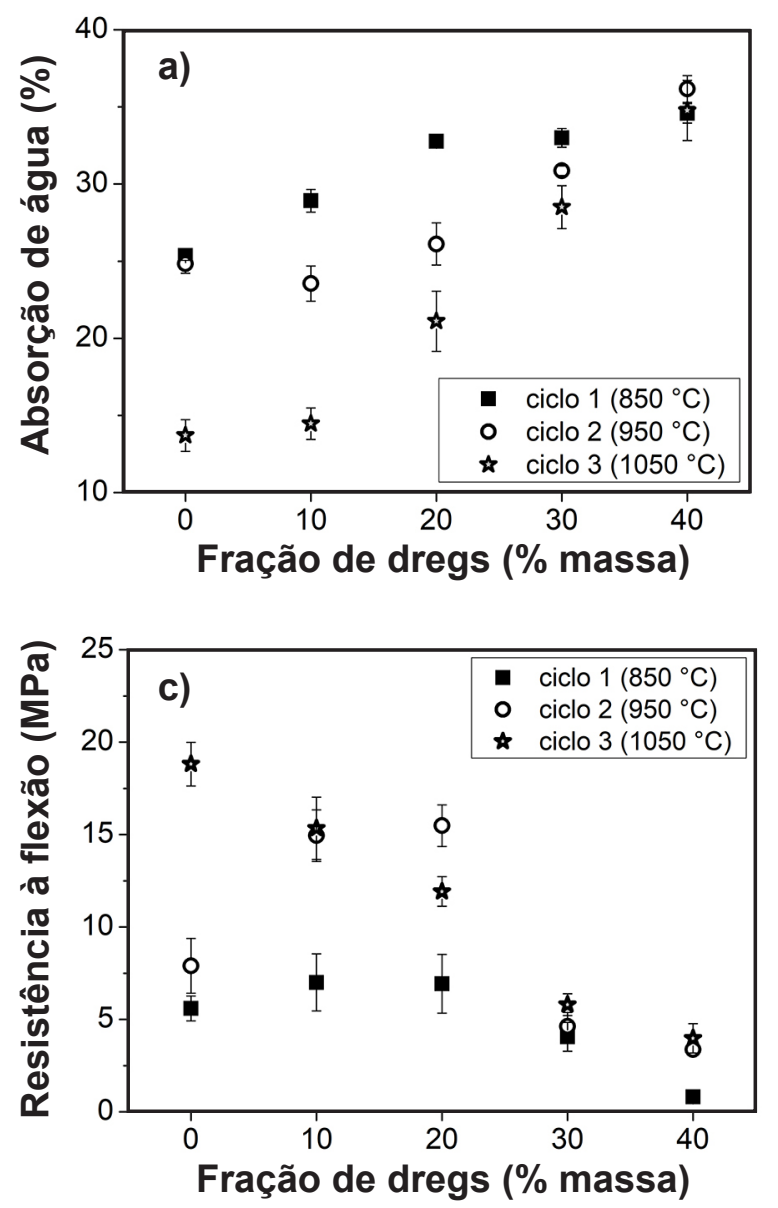

queima, devido à presença de $\mathrm{CaCO}_{3}$. Outros autores [10] obtiveram resultado semelhante com a incorporação de resíduo de mármore, também rico em carbonato de cálcio, em cerâmica vermelha. Apesar dessa tendência, nos CPs com queima a 850 ou $950{ }^{\circ} \mathrm{C}$ os valores de AA ficaram próximos ao da formulação de referência, sem resíduo, sugerindo que é possível a adição desse resíduo na fabricação de produtos de massas argilosas. Por sua vez, nos CPs sinterizados a $1050{ }^{\circ} \mathrm{C}$, apenas a composição com $10 \%$ de resíduo teve AA próxima à da argila pura, o que foi relacionado ao fato de que nessa temperatura foi possível decomposição da maior parte do carbonato presente no resíduo. Porém, a composição com $30 \%$ de resíduo e queima nas condições do ciclo 3 ainda apresentou AA superior à composição de referência com queima a 850 e $950{ }^{\circ} \mathrm{C}$, apesar da possível formação de maior volume de fase líquida durante a sinterização a $1050^{\circ} \mathrm{Ce}$ também ter sido favorecida pela presença dos óxidos fundentes provenientes do resíduo.

A resistência à flexão (Figs. 1c e 1d) apresentou tendência de crescimento com adição de até $20 \%$ de dregs, quando foi realizada sinterização em 850 ou $950{ }^{\circ} \mathrm{C}$. Esse comportamento pode ser relacionado com o aumento no teor
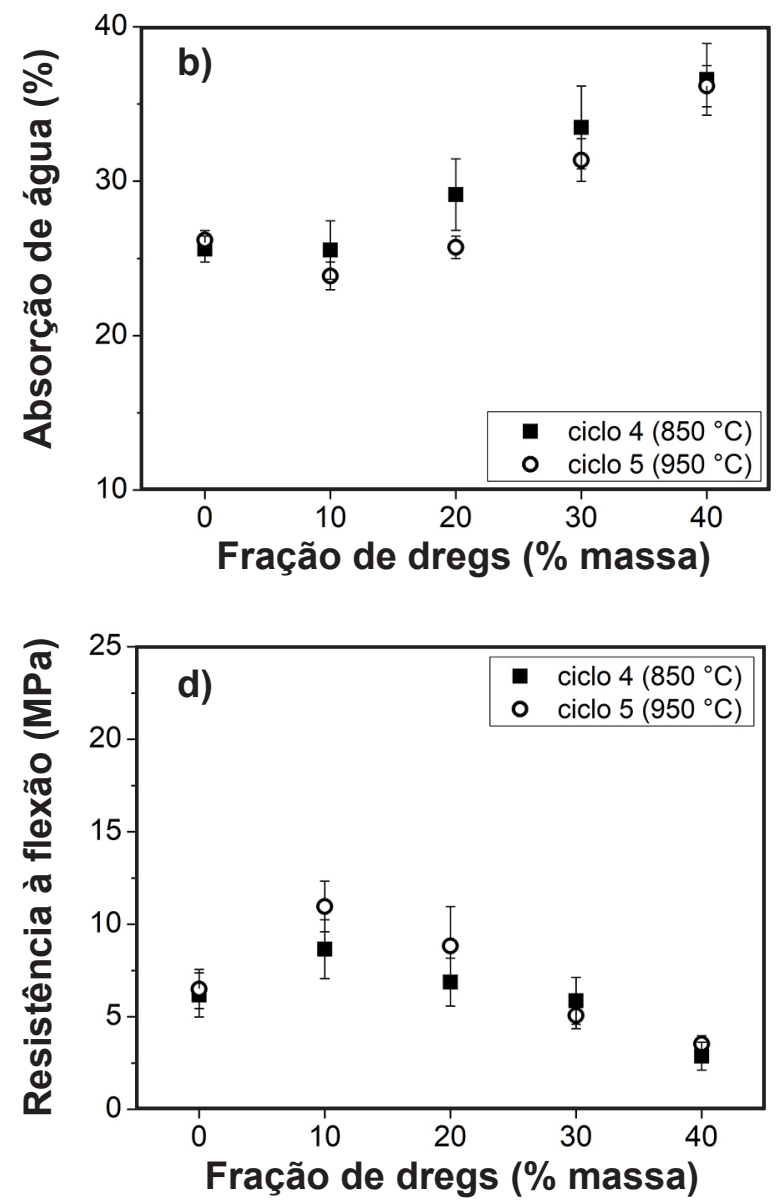

Figura 1: Absorção de água $(\mathrm{a}, \mathrm{b})$ e resistência à flexão $(\mathrm{c}, \mathrm{d})$ em função do percentual de dregs e ciclos de queima com patamar de 180 min (a,c) e $300 \min (b, d)$.

[Figure 1: Water absorption $(a, b)$ and bending strength $(c, d)$ as a function of dregs amount and firing cycles with a dwell time of 180 min $(a, c)$ and $300 \min (b, d)$.] 
de óxidos fundentes na massa argilosa, devido à incorporação do resíduo. Em 30\% e 40\% de dregs ocorreu queda devido ao aumento da porosidade, ocasionada pela liberação de $\mathrm{CO}_{2}$ durante a decomposição do carbonato presente no dregs, promovendo aumento na concentração de tensão, bem como redução da área útil em que a carga é aplicada. Em $1050{ }^{\circ} \mathrm{C}$ foi observada redução na resistência à flexão com o aumento do teor de resíduo. Assim como a AA, o comportamento da resistência mecânica nessa temperatura pode ser relacionado à calcinação total do $\mathrm{CaCO}_{3}$ presente no dregs. A liberação de gases permite a formação de uma rede de poros na amostra, o que leva à redução na resistência mecânica [22]. Portanto, o aumento de temperatura de queima de 950 para $1050{ }^{\circ} \mathrm{C}$ não foi vantajoso para a resistência mecânica das composições com resíduos, pois em ambas temperaturas os valores obtidos para resistência à flexão foram próximos, além do aumento no custo de produção relacionado ao maior gasto energético. Contudo, o aumento na temperatura máxima de queima para $1050{ }^{\circ} \mathrm{C}$ teve efeito positivo na $\mathrm{AA}$ para as composições com até $30 \%$ de dregs.

Com a ANOVA foi possível verificar se a diferença entre as médias de cada propriedade, mantendo a composição e variando o ciclo de queima, foi significativa. Na Tabela II são apresentados os valores-p para cada análise realizada. $\mathrm{O}$ valor-p permitiu comparar as médias e identificar se a diferença foi significativa quando usados diferentes ciclos de queima para a mesma composição. Quando $p<0,05$ (5\%), o fator apresentou influência sobre a variável resposta (AA ou resistência à flexão) com um nível de confiança de $95 \%$. Como encontramos $p<0,05$ em todas as análises, com exceção da AA para a composição com $40 \%$ de dregs, dentro de cada grupo existiram médias estatisticamente diferentes. Assim, para identificar quais ciclos de queima forneceram valores médios significativamente diferentes para cada propriedade, foi utilizado o teste de múltiplas comparações de Tukey. A partir do resultado do teste de Tukey (Tabela III), observouse que na composição com $40 \%$ de dregs o ciclo de queima não teve efeito significativo na $\mathrm{AA}$. Contudo, o aumento da temperatura máxima de queima influenciou na resistência à flexão dos CPs, principalmente para as formulações com até $20 \%$ de resíduo. Em geral, o tempo de patamar não influenciou nas propriedades físico-mecânicas da maior parte das composições. Assim, seria possível utilizar menor tempo de patamar na queima, sem prejuízo nessas propriedades, levando ao menor consumo energético. Além disso, nos ciclos com patamar de $300 \mathrm{~min}$, a variação na temperatura de queima de 850 para $950{ }^{\circ} \mathrm{C}$ teve influência significativa apenas na AA da formulação com $20 \%$ de dregs, sugerindo que boas propriedades físico-mecânicas podem ser mantidas com o uso de ciclos de queima longos, semelhante aos usados em indústrias de cerâmica vermelha, não requerendo uso de altas temperaturas, em torno de $950{ }^{\circ} \mathrm{C}$.

Após imersão total em água seguida de secagem, foi observado que a superfície de alguns CPs ficou esbranquiçada (Fig. 2). Esse efeito sugeriu que o resíduo não foi inertizado na massa, favorecendo a lixiviação de compostos e comprometendo a durabilidade da peça. Dessa forma, para confirmar as formulações que apresentaram

Tabela II - Valor-p obtido a partir da ANOVA.

[Table II - p-value obtained from ANOVA.]

\begin{tabular}{ccc}
\hline Formulação & $\begin{array}{c}\text { Absorção de } \\
\text { água }\end{array}$ & $\begin{array}{c}\text { Resistência à } \\
\text { flexão }\end{array}$ \\
\hline $0 \%$ dregs & 0,0 & $2,2.10^{-16}$ \\
$10 \%$ dregs & $6,7.10^{-16}$ & $5,1.10^{-9}$ \\
$20 \%$ dregs & $9,4.10^{-11}$ & $8,3.10^{-10}$ \\
$30 \%$ dregs & $5,2.10^{-5}$ & $2,2.10^{-3}$ \\
$40 \%$ dregs & 0,13 & $2,5 \cdot 10^{-8}$ \\
\hline
\end{tabular}

Tabela III - Resultados da comparação entre as médias utilizando o teste de Tukey.

[Table III - Results of means comparisons using the Tukey test.]

\begin{tabular}{ccccccccccc}
\hline & \multicolumn{1}{c}{ Absorção de água } \\
Ciclos de queima & $\begin{array}{c}0 \% \\
\text { dregs }\end{array}$ & $\begin{array}{c}10 \% \\
\text { dregs }\end{array}$ & $\begin{array}{c}20 \% \\
\text { dregs }\end{array}$ & $\begin{array}{c}30 \% \\
\text { dregs }\end{array}$ & $\begin{array}{c}40 \% \\
\text { dregs }\end{array}$ & $\begin{array}{c}0 \% \\
\text { dregs }\end{array}$ & $\begin{array}{c}10 \% \\
\text { dregs }\end{array}$ & $\begin{array}{c}20 \% \\
\text { dregs }\end{array}$ & $\begin{array}{c}30 \% \\
\text { dregs }\end{array}$ & $\begin{array}{c}40 \% \\
\text { dregs }\end{array}$ \\
\hline $1-2$ & 0 & 1 & 1 & 0 & 0 & 1 & 1 & 1 & 0 & 1 \\
$1-3$ & 1 & 1 & 1 & 1 & 0 & 1 & 1 & 1 & 1 & 1 \\
$1-4$ & 0 & 1 & 1 & 0 & 0 & 0 & 0 & 0 & 1 & 1 \\
$1-5$ & 0 & 1 & 1 & 0 & 0 & 0 & 1 & 0 & 0 & 1 \\
$2-3$ & 1 & 1 & 1 & 0 & 0 & 1 & 0 & 1 & 0 & 0 \\
$2-4$ & 0 & 0 & 1 & 1 & 0 & 0 & 1 & 1 & 0 & 0 \\
$2-5$ & 1 & 0 & 0 & 0 & 0 & 0 & 1 & 1 & 0 & 0 \\
$3-4$ & 1 & 1 & 1 & 1 & 0 & 1 & 1 & 1 & 0 & 1 \\
$3-5$ & 1 & 1 & 1 & 1 & 0 & 1 & 1 & 1 & 0 & 0 \\
$4-5$ & 0 & 0 & 1 & 0 & 0 & 0 & 0 & 0 & 0 & 0 \\
\hline
\end{tabular}

0: estatisticamente igual (diferença não significativa); 1: estatisticamente diferente (diferença significativa); ciclo 1: $850^{\circ} \mathrm{C} / 180 \mathrm{~min}$; ciclo 2: $950{ }^{\circ} \mathrm{C} / 180 \mathrm{~min}$; ciclo 3: $1050{ }^{\circ} \mathrm{C} / 180 \mathrm{~min}$; ciclo 4: $850^{\circ} \mathrm{C} / 300 \mathrm{~min}$; ciclo 5: $950{ }^{\circ} \mathrm{C} / 300 \mathrm{~min}$. 
esse efeito, foi realizado ensaio nos CPs com base na norma ASTM C67-16 [20]. As imagens resultantes após a realização deste ensaio são apresentadas na Fig. 3. Nestas imagens, a região do corpo de prova que ficou imersa em água destilada está na parte superior. Verificou-se que em todas as composições com resíduo sinterizadas a $850{ }^{\circ} \mathrm{C}(\operatorname{ciclos} 1$ e 4 , Figs. 3a e 3d) houve o surgimento de manchas brancas na superfície. Quando a sinterização foi feita a $950{ }^{\circ} \mathrm{C}$, com patamar em 180 min, as composições com $10 \%$ e $20 \%$ em massa de dregs não mostraram alteração no aspecto visual após imersão em água. Ao manter a temperatura de queima e aumentar o tempo de patamar para $300 \mathrm{~min}$ (ciclo 5, Fig. 3e), a presença de até $30 \%$ de dregs não levou à presença de manchas na superfície. Entretanto, comparando as imagens dos CPs dos ciclos 2 e 3 (Figs. 3b e 3c), notouse que o aumento na temperatura de queima para 1050 ${ }^{\circ} \mathrm{C}$, mantendo o tempo de patamar, não se mostrou benéfico para evitar as mudanças na aparência dos CPs, sugerindo que a estabilização do resíduo na massa foi mais favorecida pelo tempo disponível para reação. Portanto, considerando os ciclos de queima avaliados, é recomendado que o uso de dregs seja limitado em 30\% para que a queda na resistência mecânica, em relação à argila pura, não seja significativa. Contudo, o ciclo de queima deve ser realizado em $950{ }^{\circ} \mathrm{C}$ e com patamar de pelo menos $300 \mathrm{~min}$. Esse tempo longo para reação não é um problema para indústrias de cerâmica vermelha, pois normalmente são usados ciclos longos de queima, os quais podem ultrapassar $24 \mathrm{~h}$, entre aquecimento e resfriamento.

Foi realizada análise mineralógica nos depósitos brancos formados na superfície dos CPs (Fig. 4), onde foi identificada a presença de calcita $\left(\mathrm{CaCO}_{3}\right)$, portlandita $\left[\mathrm{Ca}(\mathrm{OH})_{2}\right]$, resultante da hidratação do $\mathrm{CaO}$, além de quartzo não reagido, proveniente da argila, e gehlenita $\left(\mathrm{Ca}_{2} \mathrm{Al}_{2} \mathrm{SiO}_{7}\right)$, desenvolvida a partir da reação entre o argilomineral e o $\mathrm{CaO}$. Dessa forma, concluiuse que a temperatura de queima não foi suficiente para decompor totalmente o carbonato de cálcio em algumas composições. Visualmente esse fenômeno foi mais pronunciado nos CPs sinterizados em $850^{\circ} \mathrm{C}$ e com maior percentual de dregs. Como em $950{ }^{\circ} \mathrm{C}$ a microestrutura deve possuir capilares de menor diâmetro, poros não

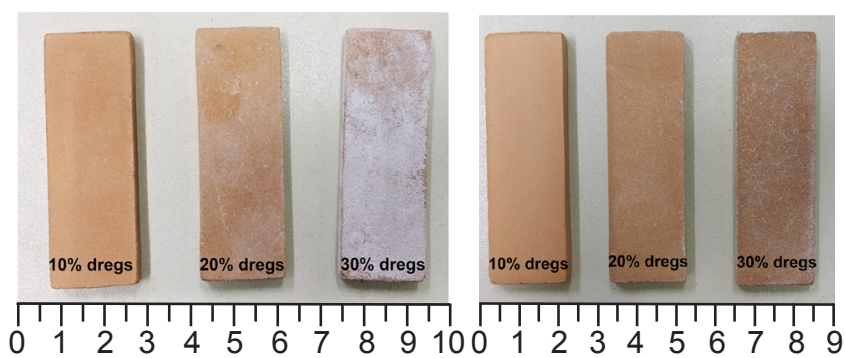

Figura 2: Imagens dos CPs com 10\%, 20\% e 30\% de dregs sinterizados a $850{ }^{\circ} \mathrm{C}$ (a) e $950{ }^{\circ} \mathrm{C}$ (b), após imersão em água.

[Figure 2: Images of specimens with 10, 20, and $30 \mathrm{wt} \%$ dregs sintered at $850^{\circ} \mathrm{C}$ (a) and $950^{\circ} \mathrm{C}($ b), after water immersion.]
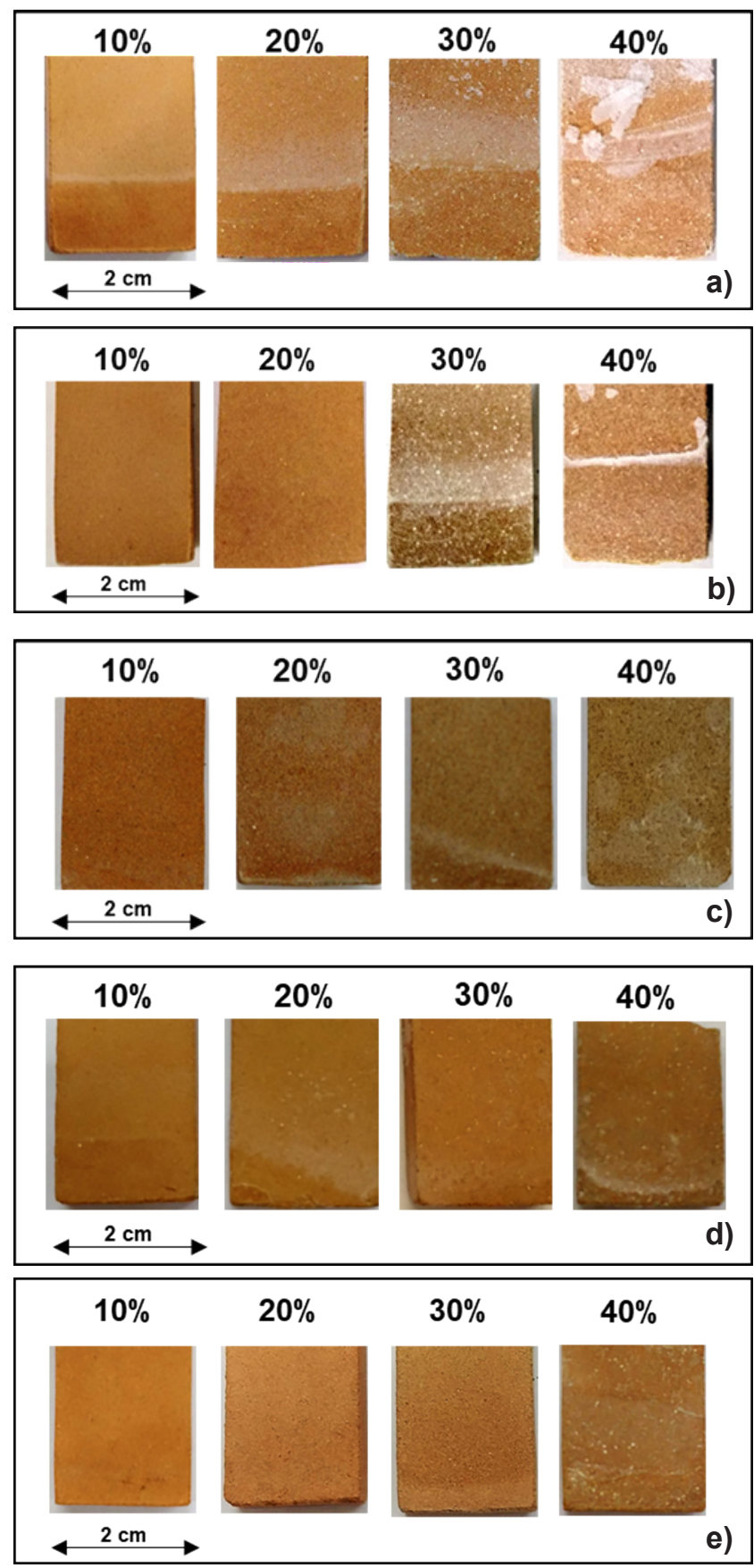

Figura 3: Imagens dos CPs sinterizados com ciclos 1 (a), 2 (b), 3 (c), 4 (d) e 5 (e), após imersão em água destilada e secagem em estufa. [Figure 3: Images of specimens sintered with cycles 1 (a), 2 (b), 3 (c), 4 (d), and 5 (e), after water immersion and drying.]

interconectados e menor absorção de água [23], além de maior teor de carbonato de cálcio decomposto em $\mathrm{CaO}$, foi minimizado o arraste do $\mathrm{CaCO}_{3}$ para superfície do CP. Outros autores [10], ao utilizar um resíduo com carbonato de cálcio em cerâmica também notaram que a calcita tende a permanecer no corpo cerâmico em menores temperaturas de sinterização, sendo que apenas acima de $1025^{\circ} \mathrm{C}$ essa fase desapareceu.

Segundo a NBR 15310:2009 [24], em cerâmica argilosa a eflorescência é definida como um depósito 


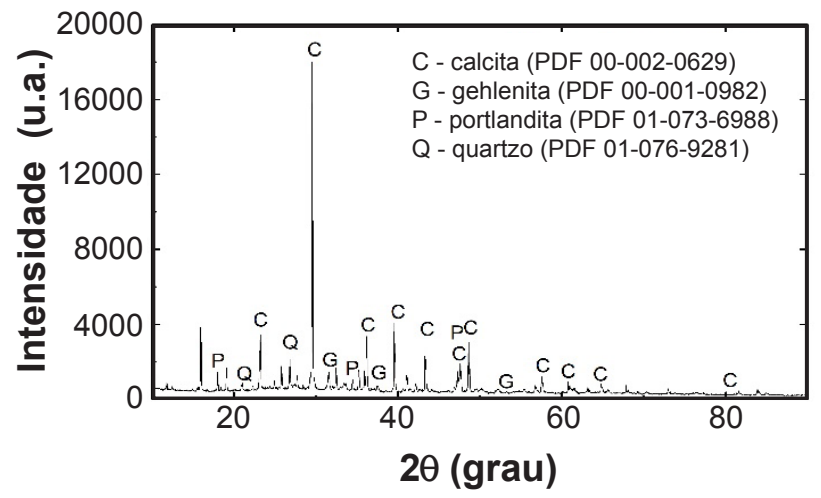

Figura 4: Difratograma de raios X da superfície do CP com $30 \%$ de dregs sinterizado em $850^{\circ} \mathrm{C}$ após imersão em água e secagem.

[Figure 4: X-ray diffraction pattern of the surface of the specimen with $30 \%$ dregs sintered at $850{ }^{\circ} \mathrm{C}$ after water immersion and drying.]

cristalino de sais solúveis na superfície da peça, decorrente do transporte de solução aquosa do interior e a evaporação da água na superfície. Portanto, por não terem sido identificados sais solúveis, como o sulfato de cálcio, esse fenômeno não pode ser denominado de eflorescência, apesar da semelhança visual. As micrografias da superfície do $\mathrm{CP}$ com $30 \%$ de dregs e queima em $850{ }^{\circ} \mathrm{C}$ (Fig. 5) mostraram que o material pulverulento na superfície dos CPs foi constituído de partículas com morfologia irregular, com sinais de cristalização identificados apenas em algumas regiões (Fig. 5c). A análise por EDS (Tabela IV) confirmou o resultado de DRX, sendo $\mathrm{O}, \mathrm{Ca}$ e $\mathrm{C}$ os elementos majoritários na maior parte dos pontos analisados. Também foram identificadas maiores quantidades de $\mathrm{Si}$ e $\mathrm{Al}$ em algumas regiões. No mapeamento elementar realizado (Fig. 6), Ca, O, C e S apresentaram distribuição homogênea na região analisada. Esses elementos foram provenientes essencialmente do resíduo adicionado, com exceção do $\mathrm{O}$ que também pode estar associado às fases desenvolvidas a partir dos constituintes da argila. Já o Si e Al estavam concentrados em algumas regiões não cobertas com o material esbranquiçado e seus maiores teores encontraram-se nos mesmos pontos, confirmando que esses elementos estavam associados, possivelmente na forma de metacaulinita. Portanto, as manchas brancas macroscópicas observadas após o ensaio de AA estão relacionadas à não reatividade de parte do resíduo com
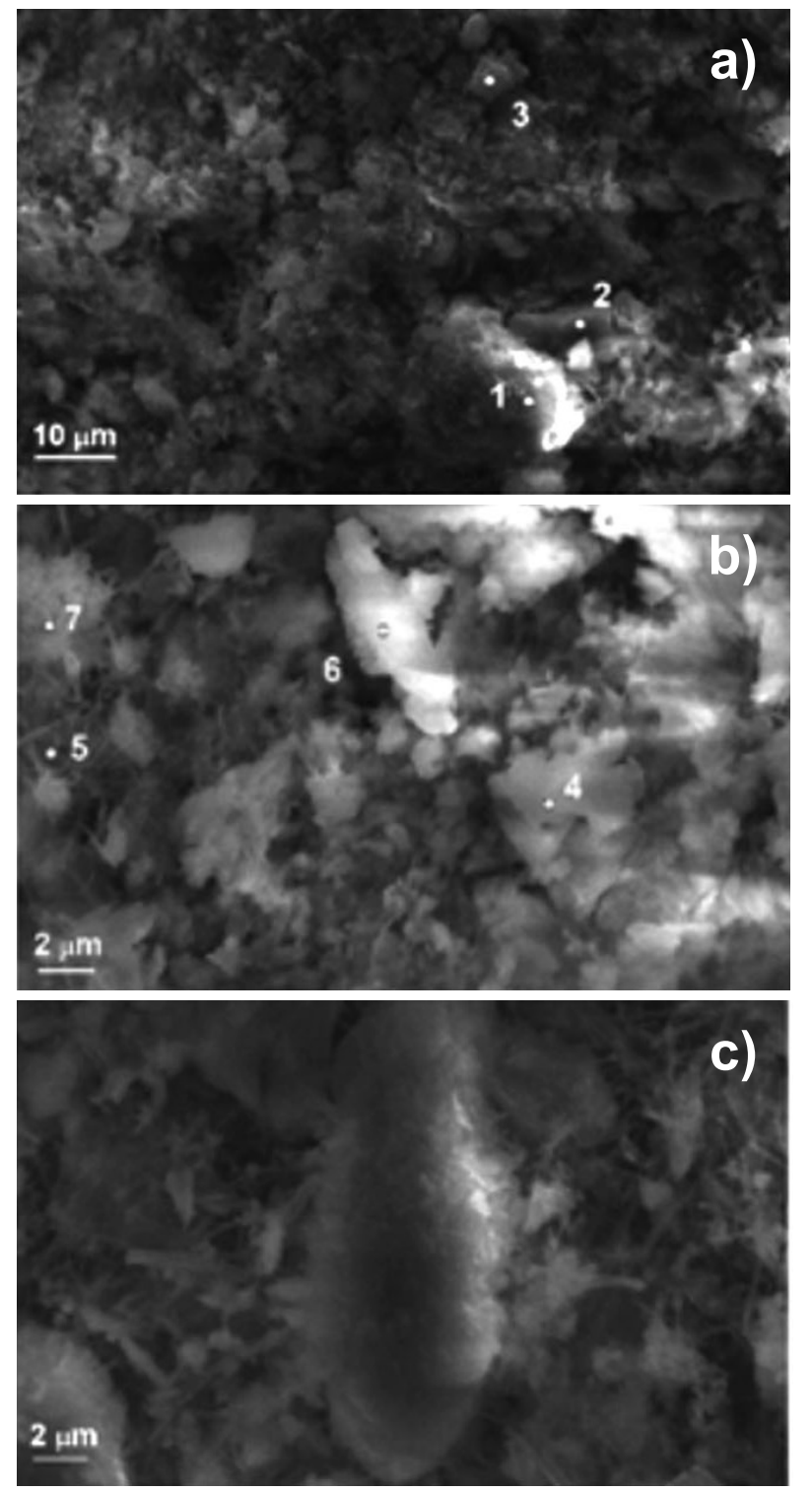

Figura 5: Micrografias de MEV com diferentes ampliações da superficie do $\mathrm{CP}$ com $30 \%$ de dregs sinterizado a $850{ }^{\circ} \mathrm{C}$ após imersão em água e secagem. Os pontos 1 a 7 indicam a localização da microanálise por EDS. [Figure 6: SEM micrographs with different magnifications of the surface of the specimen with $30 \%$ dregs sintered at $850{ }^{\circ} \mathrm{C}$, after water immersion and drying. Points 1 to 7 indicate the positions of EDS microanalysis.]

Tabela IV - Composição pontual por EDS da superfície do corpo de prova (\% em massa).

[Table IV - Composition by EDS point analysis on the specimen surface (in wt\%).]

\begin{tabular}{cccccccccc}
\hline Ponto & $\mathrm{O}$ & $\mathrm{C}$ & $\mathrm{Si}$ & $\mathrm{Al}$ & $\mathrm{Ca}$ & $\mathrm{Fe}$ & $\mathrm{Na}$ & $\mathrm{Mg}$ & $\mathrm{S}$ \\
\hline 1 & 48,1 & 15,6 & 12,4 & 11,8 & 8,2 & 1,6 & 1,2 & 0,7 & - \\
2 & 56,0 & 20,4 & 0,5 & 1,0 & 21,0 & 0,2 & - & 0,2 & 0,6 \\
3 & 52,7 & 13,2 & 7,7 & 8,8 & 14,7 & 1,9 & - & 1,1 & - \\
4 & 56,5 & 20,8 & 1,0 & 1,3 & 18,5 & 0,4 & - & 0,2 & 0,8 \\
5 & 44,8 & 11,3 & 8,3 & 7,1 & 21,9 & 2,3 & - & 2,0 & 1,5 \\
6 & 50,6 & 15,7 & 3,0 & 2,9 & 24,9 & 0,9 & - & 0,5 & 1,4 \\
7 & 52,6 & 15,1 & 4,2 & 4,9 & 18,6 & 1,2 & - & 0,8 & 2,1 \\
\hline
\end{tabular}




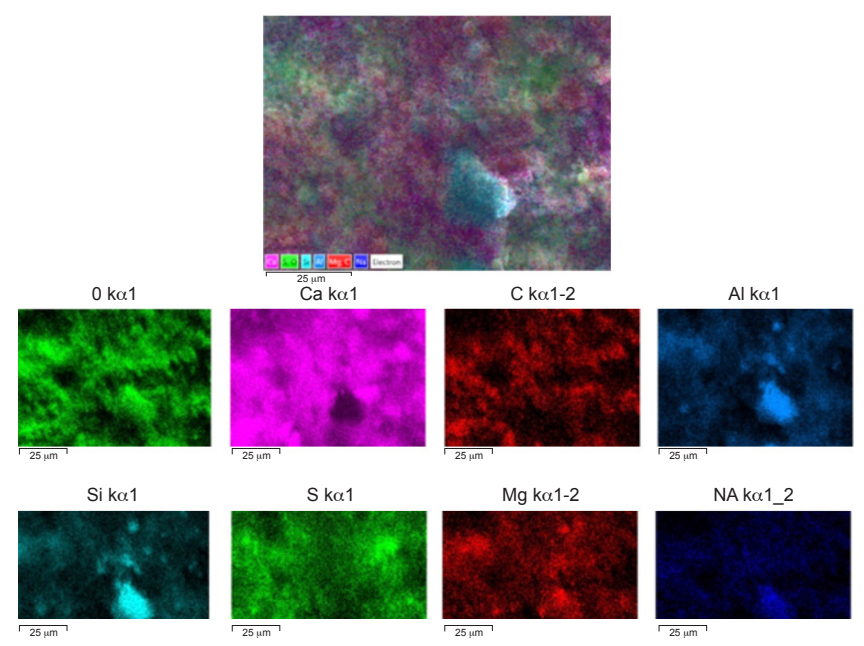

Figura 6: Imagens de mapeamento elementar por EDS da superfície do $\mathrm{CP}$ com $30 \%$ de dregs sinterizado em $850{ }^{\circ} \mathrm{C}$ após imersão em água e secagem.

[Figure 6: EDS dot mapping images of the surface of the specimen with $30 \%$ dregs sintered at $850^{\circ} \mathrm{C}$, after water immersion and drying.]

a massa argilosa. Como o ciclo de queima não foi efetivo para a imobilização das partículas do resíduo na matriz cerâmica, a presença de água e a porosidade do CP possibilitaram o arraste do $\mathrm{CaCO}_{3}$ e outros componentes do resíduo para a superfície da peça.

\section{CONCLUSÕES}

Com base nas análises realizadas, seria possível a substituição parcial de argila por dregs, dentro das proporções avaliadas. Considerando as propriedades físico-mecânicas, a variação na temperatura máxima de queima teve maior influência quando foram incorporados menores percentuais de resíduo (até 20\% em massa). Contudo, em alguns ciclos de queima a adição de dregs levou à presença de carbonato de cálcio não reagido na cerâmica, que se depositou na superfície após imersão em água. Esse fenômeno, além de ser uma limitação estética, pode comprometer a durabilidade das peças sinterizadas. Dessa forma, recomendase que a incorporação desse resíduo seja em percentual igual ou inferior a $30 \%$ em massa e o ciclo de queima deve apresentar temperatura máxima acima de $950{ }^{\circ} \mathrm{C}$ e tempo de patamar de pelo menos $300 \mathrm{~min}$, para fornecer condições necessárias à decomposição e reação do resíduo na massa. Portanto, a seleção correta do tempo de patamar bem como temperatura de queima são essenciais para estabilização do resíduo na peça sinterizada.

\section{AGRADECIMENTO}

À FAPES, pelo auxílio financeiro (processo 929/2015 71895116).

\section{REFERÊNCIAS}

[1] IBÁ, “Relatório 2019”, Ind. Bras. Árvores (2019) https://iba. org/, ac. 05/12/2019.

[2] R. Pöykiö, H. Nurmesniemi, T. Kuokkanen, P. Perämäki, Environ. Chem. Lett. 4 (2006) 37.

[3] M.C. Monte, E. Fuente, A. Blanco, C. Negro, Waste Manage. 29 (2009) 293.

[4] H. Nurmesniemi, R. Pöykiö, P. Perämäki, T. Kuokkanen, Chemosphere 61 (2005) 1475.

[5] H.C. Almeida, C.B. da Silveira, P.R. Ernani, M.L. Campos, D. Almeida, Quím. Nova 30 (2007) 1669.

[6] H. Nurmesniemi, R. Pöykiö, R.L. Keiski, Waste Manage. 27 (2007) 1939.

[7] F. Cabral, H.M. Ribeiro, L. Hilário, L. Machado, E. Vasconcelos, Bioresour. Technol. 99 (2008) 8294.

[8] J.M.S. Moreira, J.P.V.T. Manhães, J.N.F. Holanda, J. Mater. Process. Technol. 196 (2008) 88.

[9] B.C.A. Pinheiro, J.N.F. Holanda, J. Mater. Process. Technol. 209 (2009) 5606.

[10] M.A. Montero, M.M. Jordán, M.B. Almendro-Candel, T. Sanfeliu, M.S. Hernández-Crespo, App. Clay Sci. 43 (2009) 186.

[11] L. Pérez-Villarejo, F.A. Corpas-Iglesias, S. MartínezMartínez, R. Artiaga, J. Pascual-Cosp, Constr. Build. Mater. 35 (2012) 656.

[12] N. Quijorna, A. Coz, A. Andres, C. Cheeseman, Resour. Conserv. Recy. 65 (2012) 1.

[13] L. Pérez-Villarejo, S. Martínez-Martínez, B. CarrascoHurtado, D. Eliche-Quesada, C. Ureña-Nieto, P.J. SánchezSoto, Appl. Clay Sci. 105-106 (2015) 89.

[14] N. Phonphuak, S. Kanyakam, P. Chindaprasirt, J. Clean. Prod. 112 (2016) 3057.

[15] L.L. Izidio, G.W. Subtil, A.A. de Andrade, O Papel, Nota Técn. (2014) 50.

[16] E. Wolff, W.K. Schwabe, S.V. Conceição, J. Clean. Prod. 96 (2015) 282.

[17] E. Wolff, W.K. Schwabe, S.V. Conceição, J.A. SantannaGreco, M. Greco, R.R. Machado, Clean Technol. Environ. 19 (2017) 379.

[18] L.R. Rodrigues, E.R. Rodrigues, C.B. Albani, A.S. dos Reis, D.M. Louzada, V.P. Della Sagrillo, Cerâmica 65, 373 (2019) 162.

[19] P.S. Santos, Ciência e tecnologia de argilas, 1, 2a ed., Edgard Blücher, S. Paulo (1989).

[20] ASTM C67-16, "Standard test methods for sampling and testing brick and structural clay tile", Am. Soc. Test. Mater., USA (2016).

[21] F.M. Martins, J.M. Martins, L.C. Ferracin, C.J. da Cunha, J. Hazard. Mater. 147 (2007) 610.

[22] V. Mymrin, K. Alekseev, A. Nagalli, R.E. Catai, R.L.S. Izzo, J.L. Rose, H.A. Ponte, C.A. Romano, J. Clean. Prod. 120 (2016) 157.

[23] R.R. Menezes, H.S. Ferreira, G.A. Neves, H.C. Ferreira, Cerâmica 52, 321 (2006) 37.

[24] NBR 15310, "Componentes cerâmicos, telhas: terminologia, requisitos e métodos de ensaio", Ass. Bras. Norm. Técn., Rio Janeiro (2009).

(Rec. 16/12/2019, Rev. 25/03/2020, Ac. 07/04/2020) 